\title{
EEN THAISE BEKERVAAS
}

In 1996 kreeg de Vereniging van Gerrit Jan Korteling een bekervaas van enkele eeuwen voor onze jaartelling. Het stuk was geen onbekende. Al sinds 1979 was het in bruikleen op de afdeling Aziatische kunst van het Rijksmuseum.

Deze vaas op een hoge voet behoort tot het Ban Chiang-aardewerk, genoemd naar een dorp in Noord-Thailand waar vanaf de jaren ' 60 van de $20^{\mathrm{e}}$ eeuw aardewerk, brons en menselijke overblijfselen zijn gevonden, resten van een zeer oude cultuur waarvan tot dat moment niemand iets wist.

De vaas is betrekkelijk dunwandig en gemaakt van een donkere klei met een licht zeemkleurige sliblaag. De potten werden met de hand (dus zonder draaischijf) 'opgebouwd' en vervolgens afgewerkt door de wand van binnenuit te ondersteunen met een afgeplatte steen en er van buitenaf op te slaan met een plat stuk hout (paddle and anvil). De potten werden zonder oven, in het open vuur gebakken. De beschildering is uitgevoerd met een rode ijzerhoudende verf. Fraaie lusvormige motieven zijn scherp ingesneden en wit gelaten; zij versieren de schouder en voet van de vaas. De functie van de vaas is niet duidelijk. Het is in ieder geval wél duidelijk dat het aardewerk dat in Ban Chiang is opgegraven, grafgiften zijn. Uit de opgravingen blijkt dat in de periode dat dit type vazen voornamelijk werd gemaakt, het gebruik bestond de keramiek stuk te gooien in het graf. Niet bekend is in hoeverre de grafgiften overeenkomen met vormen die gebruikt werden in het dagelijks leven. De zorg waarmee het aardewerk is gemaakt en versierd is opvallend en geeft een indicatie van de hoge status die de stukken moeten hebben gehad.

De belangstelling voor Ban Chiang-aardewerk begon in 1966 toen de eerste scherven van deze toen onbekende keramiek aan deskundigen getoond werden. Door het enthousiasme over deze 'nieuwe' keramiek ontstond in het Westen snel een grote vraag naar Ban Chiang-stukken. Inwoners uit het gebied zochten en verkochten voorwerpen, graven werden overhoop gehaald en al snel werden ook zeer goed gelijkende fakes verhandeld. ${ }^{1}$ Speciale wetten en officiële opgravingen moesten hieraan paal en perk stellen. In 1974 en 1975 werden opgravingen verricht door de Thaise overheid, in samenwerking met de Universiteit van Pennsylvania. Een van de resultaten van het onderzoek is dat sindsdien een beter begrip bestaat over de chronologie van de vondsten. Keramiek met een relatief dunne scherf en spaarzame ingegrifte en geschilderde decors, zoals ook herkenbaar in deze vaas van Korteling, behoort tot de midden periode. De datering verschilt enigszins per vindplaats, maar valt tussen 1100 en 200 voor Christus. ${ }^{2}$ De late periode, gekenmerkt door keramiek met drukkere lineaire motieven in rood, duurde van 300 voor tot 300 na Christus.

Bij de officiële opgravingen in Ban Chiang is deze bekervorm niet gevonden ${ }^{3}{ }^{3}$ aM Wel bij kleinere opgravingen in andere dorpen (Ban Sang Du, Sahon Nakon) cess 


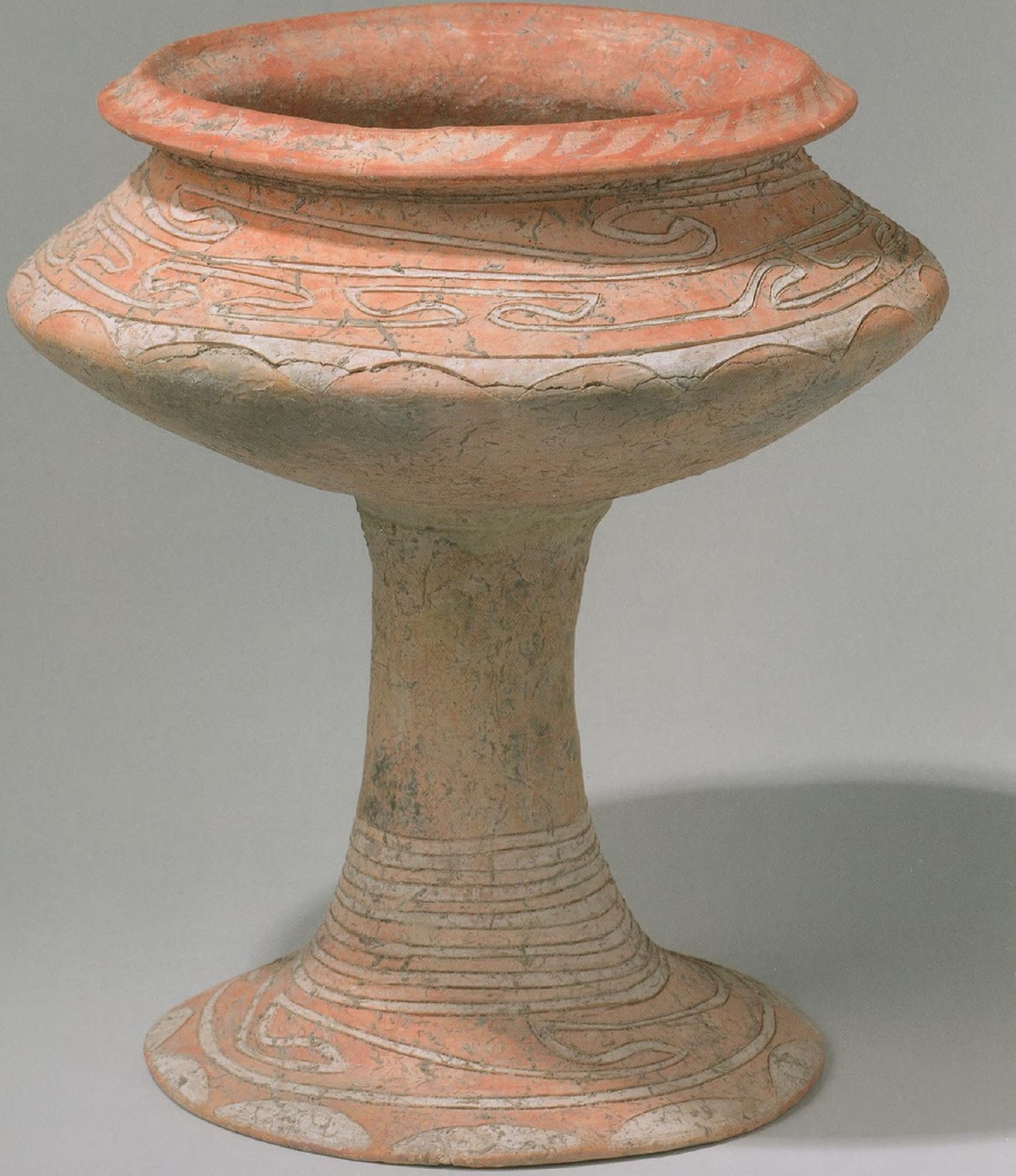


en bij illegale opgravingen in Ban Waeng. ${ }^{4}$ Mogelijk werd deze vorm specifiek in die plaatsen vervaardigd. Met kleine verschillen in vorm en decor komen deze bekervazen vrij veel voor. ${ }^{5}$ Voor zover archeologische informatie

Bekervaas, aardewerk, hoogte $23 \mathrm{~cm}$., Thailand, ca. 300-200 v.Chr. Schenking C.J. Korteling in 1996, Rijksmuseum, collectie WAK, AK-MAK-1681 beschikbaar is, zijn ze steeds afkomstig uit een vondstlaag die tot de midden periode behoort. ${ }^{6}$ De overige bekervazen worden op grond van materiaal en decors eveneens in die periode gedateerd of toegeschreven aan de overgangsperiode van de midden tot de late periode. Waarschijnlijk geldt dit ook voor deze bekervaas. Het stuk is niet kapot gegooid en moet dus stammen uit een periode waarin dat gebruik al verlaten was. De datering kan op grond hiervan verfijnd worden tot $300-200$ voor Christus.

Voorwerpen uit de Ban Chiang-cultuur waren in de jaren '70 ook in Nederland iets geheel nieuws; zij trokken veel belangstelling. De Vereniging had in 1975 twee grote potten uit de late periode gekocht bij de firma Aalderink. ${ }^{7}$ In 1978 leende Gerrit Jan Korteling deze bekervaas, samen met een bronzen lepel uit aan de tentoonstelling 'Aziatische Kunst uit het bezit van leden'. Beide stukken bleven vervolgens in het museum, eerst als bruikleen en in 1996 als geschenk aan de Vereniging.

Wereldwijd en ook in Nederland was juist rond die tijd de belangstelling voor de Ban Chiang-cultuur bijzonder groot. De eerste opgravingen waren afgerond en de publicaties waren voorhanden. In het Singermuseum in Laren was van 17 februari tot 18 maart 1979 een tentoonstelling over dit onderwerp te zien. Volgens een artikel in het Financieele Dagblad betrof het een officiële verkooptentoonstelling door de Thaise overheid. ${ }^{9}$ Galerie de Ruimte organiseerde in datzelfde jaar van 22 maart tot 20 april een verkooptentoonstelling over dit onderwerp, van een collectie bijeengebracht door Rob Grevenbroek. ${ }^{10}$

Gerrit Jan Korteling (1920-2006) werkte van 1948 tot 1976 als piloot bij de KLM. ${ }^{11}$ Hij vloog vooral op het Verre Oosten. Korteling was daarnaast enige jaren wethouder van zijn woonplaats Bennebroek. Hij was erudiet, begiftigd met een fotografisch geheugen en een bijna grenzeloze energie. Hij was een veelzijdig man: niet alleen zeer belezen, maar ook een sportman: Korteling was een verwoed rallyrijder. Als piloot vertelde hij de passagiers al graag bijzonderheden over de plaatsen waar zij overheen vlogen. Na zijn pensionering breidde dit zich uit tot het leiden van culturele reizen, onder andere in Japan. Korteling verzamelde iconen en Aziatische kunst. Op dit laatste terrein had vooral de Japanse kunst zijn belangstelling. Hij zocht niet per se het allerbeste stuk in zijn soort, maar was vooral ook geïnteresseerd in de culturele achtergronden van de voorwerpen. Hij was een actief lid en bestuurslid van de Vereniging voor Japanse kunst en liet na zijn dood een kleine groep schilderingen, prenten en tsuba na aan het Rijksmuseum en het Museum Volkenkunde in Leiden. Hoewel zijn beroep hem 'overal' ter wereld bracht en dit werk ongetwijfeld zijn belangstelling voor buiten-Europese culturen voedde, was het vliegen geen voorwaarde voor het opbouwen van zijn verzameling. Hij kocht 'overal' waar hij iets zag dat hem raakte, en was een trouwe klant van de firma Vecht in Amsterdam.

\section{Noten}

1. In 1985 werden in het Bowes Museum (Santa Ana, USA) 300 stukken 'unprovenienced' Ban Chiang-keramiek tentoongesteld, afkomstig van verzamelaarsccess 
in de VS. Zie A.J. Labbé, Ban Chiang: Art and prehistory of Northeast Thailand, Santa Ana, 1985, pp. 3-4.

2. A.J. Labbé, Prehistoric Thai Ceramics: Ban Chiang, Lopburi, and Khok Phanom Di and related sites in regional cultural perspective, Bangkok, 2002, p. 11 . Over de datering van Ban Chiang is lang gediscussieerd; de belangrijkste publicatie voor dit onderwerp is J.C. White, A revision of the chronology of Ban Chiang and its implications for the prehistory of Northeast Thailand, Ann Arbor, 1986. White was een van de deelnemers aan officiële opgravingen van 1974/75.

3. J.C. White, Discovery of a Lost Bronze Age: Ban Chiang, Philadelphia, 1982, p. 86.

4. Labbé, Op.cit. (noot 1), p. 52.

5. Chin You-di, The painted pottery of Ban Chiang, Bangkok, 1976, nrs. 76, 53, 60, 62; Ceramics of Thailand (tent.cat. Stanford University Museum of Art), Stanford, 1980, cat.nr. 4; White, Op.cit. (noot 3), nr. 145; Labbé, Op.cit. (noot 1), pp. 59-60 (zes stuks); Thai Ceramics; the James and Elaine Connell Collection (tent.cat. Asian Art Museum) San Francisco, 1993, cat.nr. 6; Labbé, Op.cit. (noot 2), nrs. 56, 57, 238.

6. Chin You-di, Ban Chiang prehistoric cultures, Bangkok, 1975, afb. 2 geeft overzicht van de vondsten per vondstlaag.

7. AK-MAK-1237 en 1238, in 1981 aangevuld met drie stukken brons eveneens aangekocht bij Aalderink: broche AK-MAK-1318, en twee armbanden AK-MAK1319-1320.

8. 22 december 1978 - 4 maart 1979, pot nr. 155, bronzen lepel nr. 157.

9. Financieel Dagblad 2 maart 1979. Veel dank aan mevrouw Emke Raassen van het Singer Museum voor deze informatie. Er verscheen ook een artikel in Laarder Courant De Bel, 20 februari 1979.

10. Met dank aan de heer Jean Nies voor deze informatie.

11. Dank aan Leo van der Meulen, Jaap Polak en Piet Hein Quarles van Ufford voor hun informatie over Gerrit Jan Korteling. 